\title{
Should clot composition affect choice of endovascular therapy?
}

Brijesh P. Mehta, MD

Raul G. Nogueira, MD

Correspondence \& reprint requests to Dr. Nogueira: raul.g.nogueira@emory.edu

\section{ABSTRACT}

Endovascular therapy has become a promising alternative for patients who are ineligible for IV thrombolysis or for whom it has failed. Greater knowledge about the composition of thromboembolic material underlying the vascular occlusion in stroke patients may provide the means for improving existing endovascular therapies and developing new treatment strategies. The objective of this article is to provide a review of clinical and experimental animal studies on the histology, imaging correlation, and ultrastructure of thromboemboli retrieved during acute ischemic stroke. Neurology ${ }^{\circledR}$ 2012;79 (Suppl 1):S63-S67

\section{GLOSSARY}

ECASS = European Cooperative Acute Stroke Study; HMCAS = hyperdense middle cerebral artery sign; $\mathbf{I A}=$ intra-arterial; ICA = internal carotid artery; $\mathbf{M C A}=$ middle cerebral artery; $\mathbf{M R}=$ magnetic resonance; $\mathbf{R B C}=$ red blood cell; $\mathbf{r t P A}=$ recombinant tissue plasminogen activator; $\mathbf{S E M}=$ scanning electron microscopy; $\mathbf{T I M I}=$ Thrombolysis in Myocardial Ischemia.

Approximately $80 \%$ of all acute ischemic strokes are due to intracranial artery occlusion. ${ }^{1,2}$ Reperfusion remains the mainstay of acute ischemic stroke treatment, as it appears to be the most beneficial of all therapeutic strategies for acute ischemic stroke. ${ }^{3-5}$ One of the major limitations of thrombolysis is related to the resistance to enzymatic degradation due to excessive cross-linking within mature embolic clots and emboli composed of cholesterol, calcium, or other debris from atherosclerotic lesions. ${ }^{6}$ Endovascular therapy with intra-arterial (IA) thrombolysis and thrombectomy has thus become a promising alternative for patients who are ineligible for IV thrombolysis or for whom it has failed; however, it is largely unknown whether selection of specific endovascular therapies should take into account clot composition, which may differ based on source of origin, site of occlusion, time to reperfusion, and other individual patient factors.

Torvik and Jorgensen ${ }^{7}$ performed postmortem analysis of "recent" occlusions in the $1960 \mathrm{~s}$, which at that time were defined as 1.5 months old. As a result of advances in neuroendovascular techniques and development of mechanical embolectomy devices, fresh clots can today be quickly retrieved from patients presenting with acute ischemic stroke. The Merci Retriever System (Concentric Medical, Mountain View, CA) has been the most widely studied device designed to remove occlusive clots impacted within cerebral arteries. ${ }^{8-10}$ Emerging knowledge about the composition of thromboembolic material retrieved from patients with acute ischemic stroke may provide the means for improving upon existing reperfusion strategies and developing new therapeutic approaches. ${ }^{11}$

CLOT COMPOSITION STUDIES Light microscopy analysis. In 2006, Marder et al. ${ }^{12}$ published results of the first systematic histologic analysis of thromboemboli removed from proximal, large intracranial cerebral arteries of patients with acute ischemic stroke. Clots were obtained with the Merci Retriever System from 25 patients (15 men, 9 women; mean age, 56.9 years). Therapy was initiated within 8 hours of symptom onset or beyond 8 hours (mean, 6.2 hours) if a large mismatch, suggestive of salvageable penumbra, was present on

From the Department of Neurology (B.P.M.), Massachusetts General Hospital, Harvard Medical School, Boston; and Departments of Neurology, Neurosurgery, and Radiology (R.G.N.), Emory University/Grady Hospital, Atlanta, GA.

Go to Neurology.org for full disclosures. Disclosures deemed relevant by the authors, if any, are provided at the end of this article. 
imaging. Vascular reperfusion after thrombectomy was evaluated with a conventional angiogram utilizing a modified Thrombolysis in Myocardial Ischemia (TIMI) scale. ${ }^{9,13}$

Their data showed no correlation of thrombus histology with presumed stroke etiology, as each thrombus was found to have similar individual components. On the basis of the algorithm for TOAST stroke subtypes, sources of embolism were cardiac (16 patients), large vessel (4 patients), arterial dissection or procedural complication (3 patients), and cryptogenic (2 patients). Light microscopy analysis identified $75 \%$ of clots with several functional features of platelet/fibrin accumulation, linear neutrophil/monocyte deposition, and erythrocyte-rich accumulation, though each clot overall exhibited distinct histologic patterns. The authors attributed the latter findings to random chaotic forces of shear and turbulence imposed on sites of thrombus formation, countering traditional dogma that a cardiac source with slow flow led to development of "red" (erythrocyte) clots, whereas high flow in arteries formed "white" (fibrin) clots. ${ }^{14}$ Additionally, extracted clots may not have fully represented the composition of native thrombi, indicating a different structure for residual material still impacted in the vessel.

Clot histology did not differ with site of thromboembolic occlusion, although there was correlation between thrombus size and location: middle cerebral artery (MCA) clots were smaller (maximum width, 3 $\mathrm{mm}$ ) than internal carotid artery (ICA) clots (maximum width, $5 \mathrm{~mm}$ ). As previously demonstrated by thrombolytic therapy trials in which MCA occlusions had higher rates of recanalization than ICA occlusions, the volume of thrombus to be dissolved might be more critical than its structure for successful revascularization. ${ }^{15}$ In this study, the site of vascular occlusion also did not correlate with reperfusion. TIMI 2-3 flow was achieved in $100 \%$ of ICA (12 of 12 ) vs $83 \%$ of MCA (10 of 12) occlusions, indicating the technical ability of the catheter to reach and remove the clots.

Finally, there was no association between thrombus histology and treatment response. There was complete recanalization of the artery (TIMI 3) in $32 \%$ of patients, partial recanalization (TIMI 2) in $56 \%$, and perfusion past the initial obstruction without distal branch filling (TIMI 1) in 12\%. The interval between symptom onset and procedure initiation did not impact recanalization rates, with TIMI 3 (5.3 hours), TIMI 2 (7.6 hours), and TIMI 1 (5.0 hours). It was hypothesized that this could be due to the thrombus being compressed very soon after occluding the artery.

Early vessel signs. Calcific emboli in more distal vessels have been seen on CT scans of patients with stroke ${ }^{16}$; however, calcific components and cholesterol crystals were notably absent in the analysis, likely because of the physical inability of the devices to reach the more distal cortical branches, where these types of emboli tend to lodge. A phase II trial for MRI of thrombi with a fibrin-specific contrast agent (EP-2104R, EPIX Pharmaceuticals, Lexington, MA) in 10 patients showed improved visualization of thrombus enhancement in several vascular territories from surrounding blood and soft tissues. ${ }^{17}$ The same probe was shown to be effective for imaging thrombi with bimodal PET and magnetic resonance (MR) in rat ICAs. ${ }^{18}$ The selective imaging of thrombi may allow for more accurate identification of their composition to assess impact on recanalization rates after thrombectomy.

The hyperdense middle cerebral artery sign (HMCAS) is a marker of thrombus in the middle cerebral artery. ${ }^{19}$ The European Cooperative Acute Stroke Study I (ECASS I) investigators performed a secondary analysis of the 620 patients who received IV recombinant tissue plasminogen activator (rtPA) or placebo and found HMCAS in 107 patients $(17.7 \%) .{ }^{20}$ The presence of HMCAS correlated with more severe initial neurologic deficits and early cerebral edema ( $p<0.0001)$. Better neurologic recovery was observed in patients with HMCAS treated with rtPA. However, the efficacy of IV thrombolysis is limited in patients with HMCAS, as demonstrated by cerebral angiography to assess treatment response, showing a recanalization rate of only $38 \%$ for proximal large-vessel occlusions. ${ }^{21}$

Radiologic signs may permit deduction of clot composition to help identify IV rtPA nonresponders. The relationship between clot composition and HMCAS on head CT or blooming artifact on MRI gradient echo scans was demonstrated in acute ischemic stroke patients. ${ }^{22}$ The findings were based on MCA occlusions in 50 patients who underwent head imaging followed by mechanical thrombectomy and subsequent histopathologic analysis of retrieved thrombi. CT scans of 20 patients showed HMCAS in $50 \%$ of cases, whereas MRI gradient echo sequences performed in 32 patients revealed blooming artifact in approximately $53 \%$. Collectively, retrieved clots were composed of $61 \%$ fibrin, 34\% red blood cells (RBCs), and 4\% white blood cells. Predominant composition among clots was 44\% fibrin, $26 \%$ RBCs, and 30\% mixed. HMCAS was more associated with RBC-dominant (100\%) and mixed (67\%) than fibrin-dominant (20\%) clot histopathology. A similar relationship was noted with blooming artifact and pathologic substrate of clots: RBC-dominant, $100 \%$; mixed, 63\%; and fibrin-dominant, 25\%. However, the presence of HMCAS and blooming artifact or 


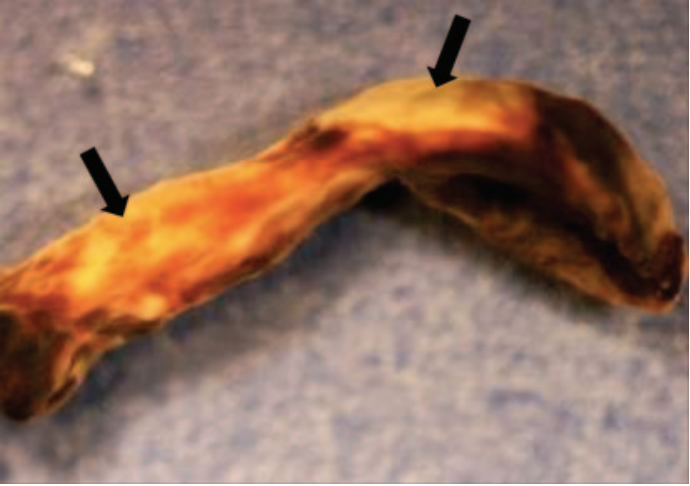

This thrombus segment features relatively smooth surface morphology. There are intensely white and red sections, suggesting exposure of certain regions to sustained high shear flow and other regions to stasis, respectively. Arrows indicate locations at which the scanning electron microscopy images shown here were taken.

thrombus histopathology was not predictive of stroke severity or functional outcome.

Scanning electron microscopy analysis. The previous studies employing light microscopy and subsequent correlation with early vessel imaging characteristics have given important insights about the histology of thrombotic lesions, ${ }^{12,22}$ although they were limited by their inability to analyze the ultrastructure of the thrombus. This issue was recently addressed by means of scanning electron microscopy (SEM) analysis of thromboembolic material retrieved from cerebral and cervical arteries of patients with acute ischemic stroke. ${ }^{23}$

Clots were retrieved by means of the Merci device $(n=16)$, Accunet device $(n=1)$, or direct thromboaspiration with a guide catheter $(\mathrm{n}=1)$. The occlusion sites included the ICA (cervical: $\mathrm{n}=2$; intracranial: $\mathrm{n}=7$; both: $\mathrm{n}=1)$, MCA $(\mathrm{n}=5)$, and basilar artery $(\mathrm{n}=3)$. Macroscopic analysis revealed the samples were diverse in size, morphology, and fragmentation. Light microscopy of the gross specimen revealed features suggestive of a range of fluid dynamic forces that may have acted on the thrombi. The red regions were located where there was likely low flow or stasis or where the thrombus was against the vessel wall, whereas white regions were likely exposed to high shear flow (figure 1). The organization of the thrombotic elements, e.g., fibrin, platelets, and red cells, was also diverse both within each thrombus and across the various thrombi; hence, these results are consistent with earlier findings of histologic examination of clots with light microscopy. ${ }^{12}$

Two distinct structural patterns could be recognized with SEM: 1) thrombus exhibiting advanced maturity, where all the thrombotic elements were so densely integrated that individual entities were not

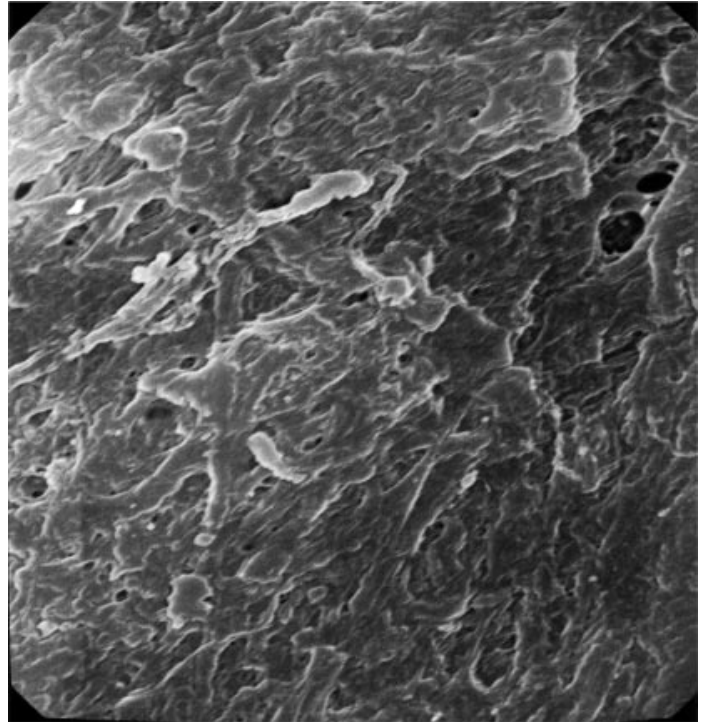

This scanning electron microscopy image at $3,000 \times$ shows a tightly integrated structure where the cross-linking of thrombotic components, i.e., red cells, fibrin, and platelets, is so dense that the individual entities are no longer apparent and have merged into a solid structure.

clearly discernible (figure 2), suggesting a well-aged and stable location that had sustained exposure to shear flow; and 2) thrombus displaying distinct fibrin strands and trapped red cells, suggesting relatively loose cross-linking, characteristic of an active region where the thrombus was still in the process of maturing and possibly of formation in regions of stasis and recirculation (figure 3 ). These patterns were seen in varying proportions among different patients. In some cases, it was possible to link specific ultrastructural findings to the presumed etiology underlying the stroke. It is noteworthy that such a wide variety of thrombi were recovered.

\section{EXPERIMENTAL IN VIVO ANIMAL STUDIES}

One of the major limitations in terms of the human research about the composition of the material underlying the causative thromboembolic occlusion in stroke is related to the fact that not all occlusions can be successfully treated by mechanical thrombectomy. As such, it is quite possible that these refractory clots have a different composition than the successfully retrieved clots. Better understanding of the nature of nonretrieved clots would be theoretically more important, since those are the ones we currently cannot adequately treat. Despite their own limitations, experimental animal stroke models may help overcome some of these barriers.

Because the proportion of fibrin and erythrocytes within thromboembolic material might play a role in 


\section{Figure $3 \quad$ Early thrombus formation}

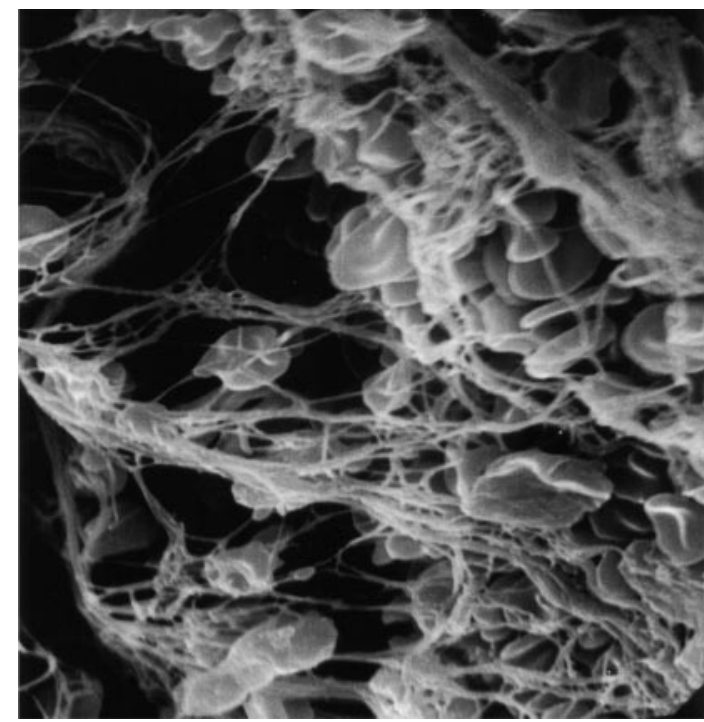

This scanning electron microscopy image at 2,400 $\times$ shows a relatively unorganized thrombotic structure, where the fibrin strands are loosely developed and individual red cells are evident. This usually indicates an active area where the thrombus is still developing in a location that has not been exposed to high shear for an extended period of time.

level of response to thrombolysis, the effect of rtPA was examined in embolic strokes due to either red (erythrocyte) or white (fibrin) clots. ${ }^{24,25} \mathrm{rtPA}$ infusion was started 30 minutes after MCA occlusion in 23 rabbits. There was enhanced lysis of red clots compared with white clots, and infarct volume was reduced only in strokes caused by red clots $(p<$ $0.01){ }^{25}$ These findings, along with the recent observations on correlation of clot composition with early vessel signs, raise the possibility of predicting pretherapeutic efficacy of thrombolysis and should be evaluated in future studies. Similarly, IA thrombolysis with rtPA an hour after ischemic stroke in a rat model has been shown to promote more rapid reperfusion, based on MR measurements of MCA occlusions, with spontaneously formed clots than with thrombin-induced fibrin-rich clots. ${ }^{26}$ This difference in response is likely attributed to a variation in mechanical properties and molecular composition between clots.

DISCUSSION The review presented here demonstrates the rationale behind evaluation of clot composition, as the studies provide important insights about the histology, imaging aspects, and ultrastructure of thromboemboli, which cause the majority of acute ischemic strokes. The histologic examination of a large number of clots with light microscopy allows for novel understanding of the pathogenesis of and therapy for large-vessel ischemic stroke. The correlation of clot histology with early vessel imaging suggests a strong association between early vessel signs (HMCAS or blooming artifact) and clots composed predominantly of RBCs, whereas absence of these imaging findings might suggest a fibrin-dominant thrombus that might be more refractory to thrombolytic drugs. SEM analysis has demonstrated different ultrastructural patterns being recognized within and among thrombi causing cerebrovascular occlusion in acute stroke patients, and additional analyses are under way. Although at this point there is not enough evidence to properly guide the selection of the most appropriate therapeutic strategy on the basis of clot composition or presumed stroke etiopathogenesis, the research discussed herein appears very promising. Increasing knowledge about the nature of thrombi, combined with emerging data from in vivo animal studies, has the potential to impact development of new reperfusion strategies and guide future endovascular treatment approaches.

\section{AUTHOR CONTRIBUTIONS}

Dr. Mehta: drafting/revising the manuscript, analysis or interpretation of data. Dr. Nogueira: drafting/revising the manuscript, study concept or design, analysis or interpretation of data, acquisition of data, study supervision.

\section{DISCLOSURE}

Dr. Mehta reports no disclosures. Dr. Nogueira has served on a scientific advisory board or data safety monitoring board for Concentric Medical, Inc; ev3 Neurovascular, Inc.; Coaxia; NeuroInterventional Therapeutics, Inc.; Rapid Medical; and Reverse Medical; and performs thrombectomy for acute ischemic stroke. Go to Neurology.org for full disclosures.

Received June 28, 2011. Accepted in final form October 26, 2011.

\section{REFERENCES}

1. Williams GR, Jiang JG, Matchar DB, Samsa GP. Incidence and occurrence of total (first-ever and recurrent) stroke. Stroke 1999;30:2523-2528.

2. American Heart Association. Heart and Stroke Facts 2003. Available at: www.americanheart.org/downloadable/heart/ 1056719919740HSFacts2003text.pdf. Accessed July 29, 2005.

3. The National Institute of Neurological Disorders and Stroke rt-PA Stroke Study Group. Tissue plasminogen activator for acute ischemic stroke. N Engl J Med 1995;333: 1581-1587.

4. Clark WM, Wissman S, Albers GW, Jhamandas JH, Madden KP, Hamilton S. Recombinant tissue-type plasminogen activator (alteplase) for ischemic stroke 3-5 hours after symptom onset: the ATLANTIS study: a randomized controlled trial: alteplase thrombolysis for acute noninterventional therapy in ischemic stroke. JAMA 1999;282: 2019-2026.

5. Adams HP Jr, Adams RJ, Brott T, et al. Stroke Council of the American Stroke Association: guidelines for the early management of patients with ischemic stroke: a scientific statement from the Stroke Council of the American Stroke Association. Stroke 2003;34:1056-1083.

6. Nogueira RG, Schwamm LH, Hirsch JA. Endovascular approaches to acute stroke, part 1: drugs, devices, and data. AJNR Am J Neuroradiol 2009;30:649-661. 
7. Torvik A, Jorgensen L. Thrombotic and embolic occlusions of the carotid arteries in an autopsy material, part I: prevalence, location and associated diseases. J Neurol Sci 1964;1:24-39.

8. Gobin YP, Starkman S, Duckwiler GR, et al. MERCI 1: a phase 1 study of mechanical embolus removal in cerebral ischemia. Stroke 2004;35:2848-2854.

9. Smith WS, Sung G, Starkman S, et al. MERCI Trial Investigators: safety and efficacy of mechanical embolectomy in acute ischemic stroke: results of the MERCI Trial. Stroke 2005;36:1432-1440.

10. Felten RP, Ogden NRP, Pena C, Provost MC, Schlosser MJ, Witten CM. The Food and Drug Administration medical device review process: clearance of a clot retriever for use in ischemic stroke. Stroke 2005;36:404-406.

11. Molina C, Saver JL. Extending reperfusion therapy for acute ischemic stroke: emerging pharmacologic, mechanical, and imaging strategies. Stroke 2005;36:2311-2320.

12. Marder VJ, Chute DJ, Starkman S, et al. Analysis of thrombi retrieved from cerebral arteries of patients with acute ischemic stroke. Stroke 2006;37:2086-2093.

13. Williams DO, Borer J, Braunwald E, et al. Intravenous recombinant tissue-type plasminogen activator in patients with acute myocardial infarction: a report from the NHLBI thrombolysis in myocardial infarction trial. Circulation 1986;73:338-346.

14. Chaves CJ, Caplan LR. Heparin and oral anticoagulants in the treatment of brain ischemia. J Neurol Sci 2000;173:3-9.

15. Kim YS, Garami Z, Mikulik R, Molina CA, Alexandrov AV. CLOTBUST Collaborators: early recanalization rates and clinical outcomes in patients with tandem internal carotid artery/middle cerebral artery occlusion and isolated middle cerebral artery occlusion. Stroke 2005;36:869 871.

16. Oliveira-Filho J, Massaro AR, Yamamoto F, Bustamante L, Scaff M. Stroke as the first manifestation of calcific aortic stenosis. Cerebrovasc Dis 2000;10:413-416.

17. Spuentrup E, Botnar RM, Wiethoff AJ, et al. MR imaging of thrombi using EP-2104R, a fibrin-specific contrast agent: initial results in patients. Eur Radiol 2008;18:1995-2005.
18. Uppal R, Catana C, Ay I, Benner T, Sorensen AG, Caravan $P$. Bimodal thrombus imaging: simultaneous PET/MR imaging with a fibrin-targeted dual PET/MR probe: feasibility study in rat model. Radiology 2011;258: 812-820.

19. Gacs G, Fox AJ, Barnett HJM, Vinuela F. CT visualization of intracranial arterial thromboembolism. Stroke 1983;14:756-762.

20. Manelfe C, Larrue V, von Kummer R, et al. Association of hyperdense middle cerebral artery sign with clinical outcome in patients treated with tissue plasminogen activator. Stroke 1999;30:769-772.

21. Wolpert SM, Bruckmann H, Greenlee R, Wechsler L, Pessin MS, del Zoppo GJ, rt-PA Acute Stroke Study Group. Neuroradiologic evaluation of patients with acute stroke treated with recombinant tissue plasminogen activator. AJNR Am J Neuroradiol 1993;14:3-13.

22. Liebeskind DS, Sanossian N, Yong WH, et al. CT and MRI early vessel signs reflect clot composition in acute stroke. Stroke 2011;42:1237-1240.

23. Nogueira RG, Sukavaneshvar S, Rabinov JD, et al. Scanning electron microscopy analysis of thromboembolic material retrieved from cerebral and cervical arteries of patients with acute ischemic stroke. Presented at the International Stroke Conference; 2008.

24. Jang IK, Gold HK, Ziskind AA, et al. Differential sensitivity of erythrocyte-rich and platelet-rich arterial thrombi to lysis with recombinant tissue-type plasminogen activator: a possible explanation for resistance to coronary thrombolysis. Circulation 1989;79:920.

25. Kirchhof K, Sikinger M, Welzel T, Zoubaa S, Sartor K. Does the result of thrombolysis with recombinant tissuetype plasminogen activator (rt-PA) in rabbits depend on the erythrocyte- and fibrin-content of a thrombus? Rofo 2004;176:98-105.

26. Niessen F, Hilger T, Hoehn M, Hossmann KA. Differences in clot preparation determine outcome of recombinant tissue plasminogen activator treatment in experimental thromboembolic stroke. Stroke 2003;34:2019-2024. 


\title{
Neurology
}

\author{
Should clot composition affect choice of endovascular therapy? \\ Brijesh P. Mehta and Raul G. Nogueira \\ Neurology 2012;79;S63-S67 \\ DOI 10.1212/WNL.0b013e3182695859
}

This information is current as of September 24, 2012

\section{Updated Information \&}

Services

References

Subspecialty Collections

Permissions \& Licensing

Reprints including high resolution figures, can be found at:

http://n.neurology.org/content/79/13_Supplement_1/S63.full

This article cites 24 articles, 16 of which you can access for free at: http://n.neurology.org/content/79/13_Supplement_1/S63.full\#ref-list-1

This article, along with others on similar topics, appears in the following collection(s):

All Cerebrovascular disease/Stroke

http://n.neurology.org/cgi/collection/all_cerebrovascular_disease_strok e

All Imaging

http://n.neurology.org/cgi/collection/all_imaging

Information about reproducing this article in parts (figures,tables) or in its entirety can be found online at:

http://www.neurology.org/about/about_the_journal\#permissions

Information about ordering reprints can be found online:

http://n.neurology.org/subscribers/advertise

Neurology ${ }^{\circledR}$ is the official journal of the American Academy of Neurology. Published continuously since 1951, it is now a weekly with 48 issues per year. Copyright Copyright $@ 2012$ by AAN Enterprises, Inc.. All rights reserved. Print ISSN: 0028-3878. Online ISSN: 1526-632X.

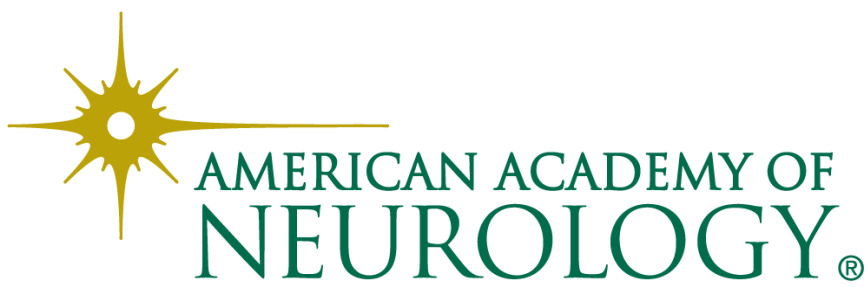

